\title{
Population biology of Anguillicola crassus in the final host Anguilla anguilla
}

\author{
K. Thomas, F. Ollevier \\ Zoological Institute, Laboratory for Ecology and Aquaculture, Catholic University of Leuven, Naamsestraat 59, B-3000 Leuven, \\ Belgium
}

\begin{abstract}
Eels were sampled twice a month (March 1990 through March 1991) at the Kolenhaven (Albertcanal, Genk, Belgium) and examined for Anguillicola crassus nematodes in the swimbladder. Averaged over all samples, $90.2 \%$ of the 345 eels were infected with a mean intensity (averaged for all stages) of 17 nematodes. Thirty-one percent of all nematodes, which were adult worms or their remnants, were present in the swimbladder lumen, while the other $69 \%$ which consisted of the third or fourth larval stage and preadults were found in the swimbladder wall. No clear seasonal fluctuations in parasite prevalence or mean intensity were observed. Both $L_{3}$-larvae and mature adult worms were present throughout the year. Eggs or $\mathrm{L}_{2}$-larvae were observed in $41 \%$ of the infected eels. This presence showed no seasonal pattern, though it was positively correlated with eel length: massive concentrations of $L_{2}$-larvae were only found in eels bigger than $40 \mathrm{~cm}$. A positive but weak correlation between eel length and number of adult nematodes in the swimbladder was significant, while no correlation was found between eel length and total parasite burden
\end{abstract}

\section{INTRODUCTION}

Anguillicola crassus is a parasitic nematode of the eel (Anguilla spp.) which originates from Southeast Asia (Kuwahara et al. 1974) and was introduced into Europe in the early 1980's (e.g. Belpaire et al. 1989a).

The life cycle of Anguillicola crassus has been studied experimentally by De Charleroy et al. (1990). The adult nematode lives in the swimbladder lumen of the European eel Anguilla anguilla L. Intermediate hosts are mainly copepods, but ostracods can also be infected experimentally (authors' unpubl. data; Petter et al. 1990). Other fish species may act as paratenic hosts for $A$. crassus, as $\mathrm{L}_{3}$-larvae have been found in various fish species (De Charleroy et al. 1990, Haenen \& van Banning 1990, Höglund \& Thomas 1992, Thomas \& Ollevier 1992).

The aim of this study was to investigate the population biology of Anguillicola crassus, especially the possible seasonal patterns in prevalence and maturation of the nematode. Variation in prevalence and mean intensity of various stages in different size classes of eels was examined and the use of paratenic hosts in the life cycle was suggested by this data.

\section{MATERIAL AND METHODS}

During a 13 mo period (March 1990 through March 1991) eels were sampled twice a month at the Kolenhaven, a dead-end side-arm of the Albertcanal, close to Genk, Belgium ( $\left.51^{\circ} \mathrm{N}, 5^{\circ} 5^{\prime} \mathrm{E}\right)$. A full description of this sampling place is given by Thomas \& Ollevier (1992). The water temperature (measured daily and averaged over $1 \mathrm{mo}$ ) reached a maximum in August $\left(24.5^{\circ} \mathrm{C}\right)$ and a minimum in February $\left(7.0^{\circ} \mathrm{C}\right)$. In total, 345 eels were sampled, of which 189 were taken from the intake screens of the power plant and an additional 156 were caught with fykes in front of the inlet. The screens were always emptied twice a week thus eels never remained there for more than $3 \mathrm{~d}$. Eels were measured, weighed and dissected at the laboratory. Their weight varied between 0.7 and $1426 \mathrm{~g}$ (mean: $318.9 \mathrm{~g}$ ) with a length between 9.5 and $96.5 \mathrm{~cm}$ (mean: $47.8 \mathrm{~cm}$ ). The swimbladder was then opened, adult nematodes counted, sexed and preserved; the swimbladder wall was pressed between glassplates and a stereomicroscope with transmitted light was used to identify larvae and preadult worms 
All worms present in the lumen - i.e. adult male and female worms, remnants from both sexes and undeterminable remnants - are hereafter referred to as 'lumen worms'. Worms present in the swimbladder wall hereafter referred to as 'wall worms') were assigned to 1 of the following groups: small $\mathrm{L}_{3}$-larvae, grown $\mathrm{L}_{3}$-larvae, $\mathrm{L}_{4}$-larvae, preadult male and female worms. No clear criteria to differentiate grown $\mathrm{L}_{3}$-larvae from $\mathrm{L}_{4}$-larvae are available from the literature and in several cases it was difficult to differentiate them in routine examinations of the swimbladder wall. Growing $\mathrm{L}_{3}$-larvae become less mobile, their intestine stains darker and the triangular lips disappear. Complete immobile larvae with a darkly stained intestine which occupied nearly the whole width of the worm, with a shortened oesophagus and still no buccal cavity present, were identified as fourth stage larvae in this study. This stage might exist just for a short period as is known for many nematodes (Chitwood \& Chitwood 1950), so it cannot be excluded that some of the so-called $\mathrm{L}_{4}$-larvae could still be $\mathrm{L}_{3}$-larvae. Also dead larvae with a nontypical appearance, which often occurred in small eels and also in the retia mirabilia, could not be assigned to the $\mathrm{L}_{3}$ - or $\mathrm{L}_{4}$-stage with certainty. As we could observe the exsheathment to the adult stage occurs in the swimbladder wall (in contrast to what is stated by van Banning \& Haenen 1990) and those preadults preadult and adult worms do not belong to a different stage - leave the wall and will be called adults once arrived in the lumen. Most preadults in this study have been found within the sheath of the fourth stage. Presence of eggs, which contain $\mathrm{L}_{2}$-larvae, was recorded and an estimate of their amount was made. Each eel was assigned to an infection degree class concerning all nematodes in lumen and wall: (A) not infected; (B) infected and all nematodes alive; (C) live and dead nematodes present; (D) live (and dead) nematodes present and a brown fluid or solid decaying material; (E) all nematodes dead and eventually brown material present; (F) no nematodes present but indication of a previously infected swimbladder (a heavily thickened wall, a few $\mathrm{L}_{2}$-larvae, black incrustations in the wall).

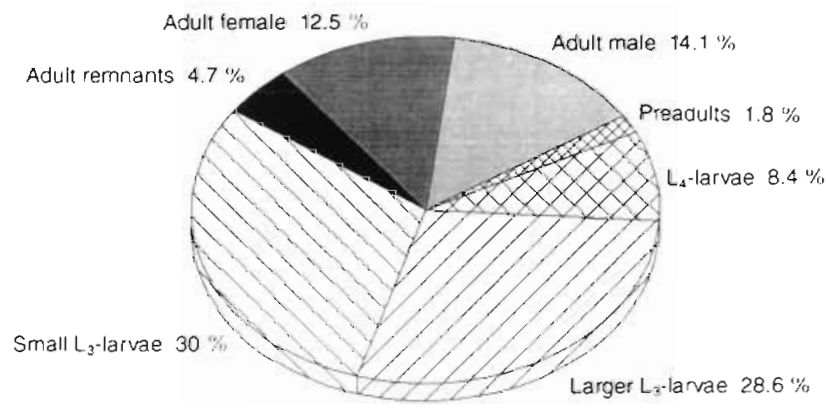

Fig. 1. Anguillicola crassus, Anguilla anguilla. Relative percentages of the different stages of nematode in eels
Statistical analysis of the data included logarithmic regression analysis, Mann-Whitney-U-test and Spearman's rank correlation coefficients. The variance to mean ratio $\left(\mathrm{s}^{2} / \bar{x}\right)$ of parasite abundance was calculated to provide an index of the degree of overdispersion of Anguillicola sp. in different size classes and different months. The terms prevalence, (mean) intensity and abundance are used according to the recommendations of Margolis et al. (1982)

\section{RESULTS}

\section{Prevalence and abundance}

Anguillicola crassus was the only parasite species found in the swimbladder of eel. Prevalence of infection was on average $90.2 \%$ on a total of 345 eels.

The intensity of infection varied between 0 and 227 parasites per fish; the total number of nematodes found being 5294, with an average mean intensity of 17 nematodes per infected eel and an abundance of 15.4 per eel. Only 1657 of them (31.3\%) were adults found in the lumen, while most nematodes were found in the $\mathrm{L}_{3}$ - or $\mathrm{L}_{4}$-stage $(67 \%)$ (Fig. 1). The ratio of male and female parasites (sum of adults, preadults and remnants) was close to equality ( 828 male worms, 824 female worms). This is in accordance with data of Belpaire et al. (1989b).

Variance to mean ratio for all nematodes was 56.8 . This ratio, calculated for each stage separately, was always greater than 1, ranging from 1.5 and 1.7 for male and female preadults to 5.6 and 5.7 for male and female aduits to 14.5 and 65.3 for grown and small $\mathrm{L}_{3}$ larvae. These data indicate a high degree of parasite overdispersion which is almost entirely due to the overdispersion of the third larval stage.

A thickened fibrotic swimbladder wall was frequently found, but rupture, resulting in the presence of free adult worms in the body cavity, has never been observed.

\section{Influence of infection on condition of eel}

Logarithmic regression analysis of length against weight of the eels did not reveal important significant differences, neither in the intercept nor in the slope of the regression line. Taking into account only the number of lumen worms, a weakly significant difference in the intercept and slope $(p<0.05)$ existed between non-infected and slightly infected eel (with 0 to 5 adult nematodes), but not between non-infected and heavily infected eel (with more than 5 adult nematodes). For wall worms, the same weak significant differences were observed but only in the slope. 
Regarding the total number of worms, weak significant differences were noted between non-infected eels and 2 groups with moderate numbers of worms. As there were no significant differences between non- and heavily infected eel, the condition of the eel does not seem to be influenced by Anguillicola crassus.

\section{Fykes versus screens}

Half of the eels were caught by fykes $(n=156)$ and half were sampled at the inlet screens of the power plant ( $n=189$ ). Except for March 1990, eels were examined from both sites every month. There was no significant difference in prevalence of infection nor in mean abundance (Table 1). However, a significant

Table 1. Anguillicola crassus, Anguilla anguilla. Prevalence and mean abundance of nematodes in eels caught by fykes and at the inlet screens of the powerplant. Wall worms: worms present in the swimbladder wall (see 'Material and methods'); lumen worms: worms present in the lumen

\begin{tabular}{|lccc|}
\hline & Screens & Fykes & $\begin{array}{c}\text { Mann-Whitney } \\
U \text {-test }\end{array}$ \\
\hline All eels & & & \\
Number of eels & 189 & 156 & \\
Prevalence (\%) & 91 & 89.1 & -- \\
$\begin{array}{l}\text { Mean abundance of } \\
\quad \text { Wall worms }\end{array}$ & 13.2 & 7.3 & $\mathrm{p}=0.003$ \\
$\quad$ Lumen worms & 4.1 & 5.8 & $\mathrm{p}=0.002$ \\
$\quad$ Total worms & 17.3 & 13.1 & $\mathrm{p}=0.4$ \\
Eels between 30 and $\mathbf{8 0} \mathrm{cm}$ & & \\
$\begin{array}{l}\text { Number of eels } \\
\text { Prevalence (\%) }\end{array}$ & 94 & 144 & \\
Mean abundance of & 92.6 & 89.6 & - \\
$\quad$ Wall worms & 18.1 & 6.0 & $\mathrm{p}=0.3$ \\
$\quad$ Lumen worms & 6.2 & 5.0 & $\mathrm{p}=0.8$ \\
$\quad$ Total worms & 24.3 & 11.6 & $\mathrm{p}=0.3$ \\
\hline
\end{tabular}

difference in mean abundance was observed for the lumen and wall worms taken separately. As the length frequency distribution of eels from both sites differed (Fig. 2), no significant differences in abundance between screens and fykes remained after eliminating eels smaller than $30 \mathrm{~cm}$ (only found on the screens) and those bigger than $80 \mathrm{~cm}$ (only found in the fykes) (Table 1). Small eels cause the significant statistical difference between fykes and screens, which has thus probably no biological meaning, and length of eel is more important (see below).

Nevertheless, the mean number of nematodes remains higher in eels from the screens from the same size classes. This is due to a few eels carrying more than 100 wall worms, of which 7 were caught at the

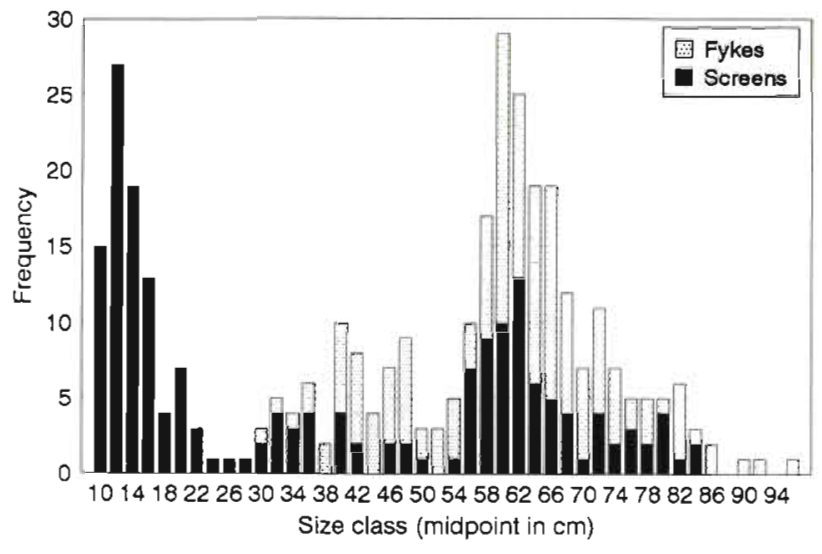

Fig. 2. Anguilla anguilla. Length-frequency distribution of eels from the inlet screens of the powerplant and fykes in the Kolenhaven (Albercanal)

screens and only 1 in the fykes. Possible transmission on the screens where fish can remain for up to $3 \mathrm{~d}$ cannot be excluded, thus this difference might or might not have a biological meaning.

Considering the infection degree classes in eels, a higher percentage of uninfected eels (Class A) and infected eels with all live worms (Class B) were found in the fykes, whereas more eels with remnants (Classes $C \& D$ ) or all dead worms (Class E) were obtained from the screens. This difference can be explained by the same difference in length frequency of the eels caught by fykes and screens (Figs. $2 \& 3$ ). When eels smaller
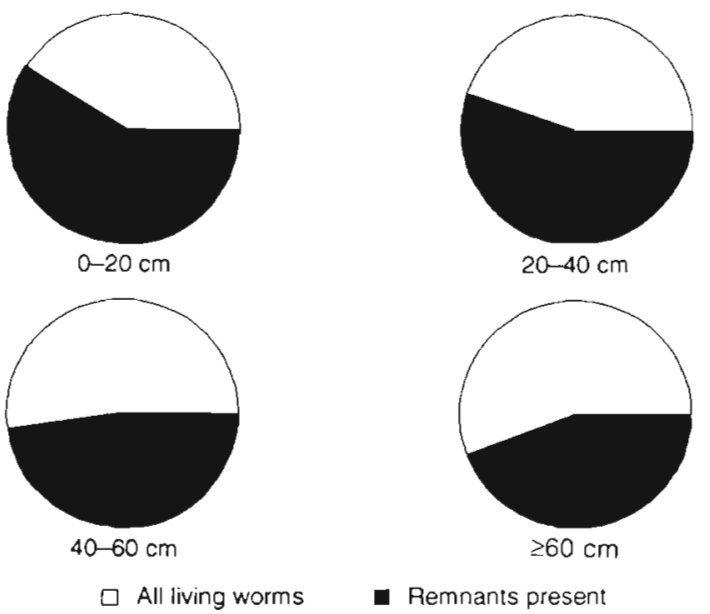

Remnants present

Fig. 3. Anguillicola crassus, Anguilla anguilla. Percentage of eels with only living worms (Class B) and eels with remnants present (Classes C, D \& E) in the 4 size classes

than $30 \mathrm{~cm}$ are excluded, the same tendency can be seen, but is not significant.

The absence of significant differences between eels from the screens and those caught by fykes made it 
possible to combine them in the study for seasonal patterns.

\section{Eel length and Anguillicola crassus infection}

Eels examined varied in length between 9.5 and 96.5 $\mathrm{cm}$ (Fig. 2). The 2 major groups are small eels between 10 and $20 \mathrm{~cm}$ and larger ones between 50 and $70 \mathrm{~cm}$.

Prevalence of infection did not differ among the various size classes (Table 2). Taking into account only the lumen worms, prevalence increases by $30 \%$ from the smallest up to the largest size-class. In eels smaller than $20 \mathrm{~cm}$ maximum number of worms, mean number and variance to mean ratio were lowest, except for the mean abundance of the wall worms. Overdispersion, as measured by the variance to mean ratio, was thus lowest in the smallest size class (Table 2).

Correlation analyses (Table 3 ) between length of eel and abundance of lumen and wall worms taken separately or pooled together, revealed a significant positive relationship between length and abundance of Iumen worms and a negative correlation between length and abundance of wall worms, which resulted in no correlation between total abundance and length (Table 3). Logarithmic transformation $\left[\log _{10}(x+1)\right]$ or exclusion of the eels with more than 100 wall worms showed similar correlations. Though significant, these correlations are small and length of eel explains only a small percentage of the variability observed in abundances.

Small infective $\mathrm{L}_{3}$-larvae were found in all size classes, even in the very large eels. Five eels which contained more than 100 small $\mathrm{L}_{3}$-larvae measured between 33.2 and $71.9 \mathrm{~cm}$. Eels smaller than $20 \mathrm{~cm}$ never carried more than 14 small $\mathrm{L}_{3}$-larvae and the negative correlation between length and wall worms was due more to a higher occurrence of grown $\mathrm{L}_{3}$ larvae and $\mathrm{L}_{4}$-larvae in small eels.

Very few small eels had more than 10 adult worms (which remain small), while the mean abundance and maximum number of lumen worms significantly increases with increasing size (Tables $2 \& 3$ ). Small eels $(<15 \mathrm{~cm})$ often showed a very hardened swimbladder with a narrow or no lumen left and in those swimbladders larvae and preadults were found dead or with a non-typical appearance. They die off probably due to a shortage of space to live in. Considering the infection degree in the various size classes, the larger eels have relatively more living worms only (infection degree Class B) than the smaller size classes (Fig. 3). In accordance with the observation that development into adult worms is related to the length of the eel, the new generation - i.e. $\mathrm{L}_{2}$-larvae - occurs in higher amounts in large eels. In small eels they do occur but in small concentrations, and only eels larger than $40 \mathrm{~cm}$ have been seen with massive concentrations of $\mathrm{L}_{2}$-larvae (Fig. 4).

Adult remnants occurred in every size class, but mean abundance (0.22) and maximum no. (=3) were lowest in eels smaller than $20 \mathrm{~cm}$.

\section{Seasonal dynamics of Anguillicola crassus}

Seasonal variation in prevalence, mean intensity, abundance and variance to mean ratio is presented in Table 4. Prevalence was high throughout the sampling

Table 2. Anguillicola crassus, Anguilla anguilla. Prevalence of infection, mean abundance, maximum no. and variance to mean ratio of nematodes in different eel size classes

\begin{tabular}{|c|c|c|c|c|}
\hline & \multicolumn{4}{|c|}{ Size class $(\mathrm{cm})$} \\
\hline & $9.5-<20$ & $20-<40$ & $40-<60$ & $60-96.5$ \\
\hline No. examined & 82 & 32 & 89 & 142 \\
\hline Prevalence $(\%)$ & 89 & 90.6 & 86.5 & 93.0 \\
\hline Prevalence of lumen worms $(\%)$ & 57.3 & 68.8 & 73.0 & 87.3 \\
\hline \multicolumn{5}{|l|}{ Wall worms } \\
\hline Mean abundance & 9.0 & 17.7 & 7.4 & 11.8 \\
\hline Max. no. & 62 & 184 & 109 & 194 \\
\hline $\mathrm{V} / \mathrm{m}$ ratio & 13.2 & 98.2 & 44.6 & 75.1 \\
\hline \multicolumn{5}{|l|}{ Lumen worms } \\
\hline Mean abundance & 1.5 & 4.5 & 4.7 & 6.9 \\
\hline Max. no. & 15 & 31 & 24 & 41 \\
\hline $\mathrm{V} / \mathrm{m}$ ratio & 3.1 & 9.5 & 8.0 & 11.2 \\
\hline \multicolumn{5}{|l|}{ Total } \\
\hline Mean abundance & 10.5 & 22.2 & 12.1 & 18.8 \\
\hline Max. no. & 66 & 215 & 111 & 227 \\
\hline $\mathrm{V} / \mathrm{m}$ ratio & 12.8 & 92.9 & 35.7 & 68.9 \\
\hline
\end{tabular}




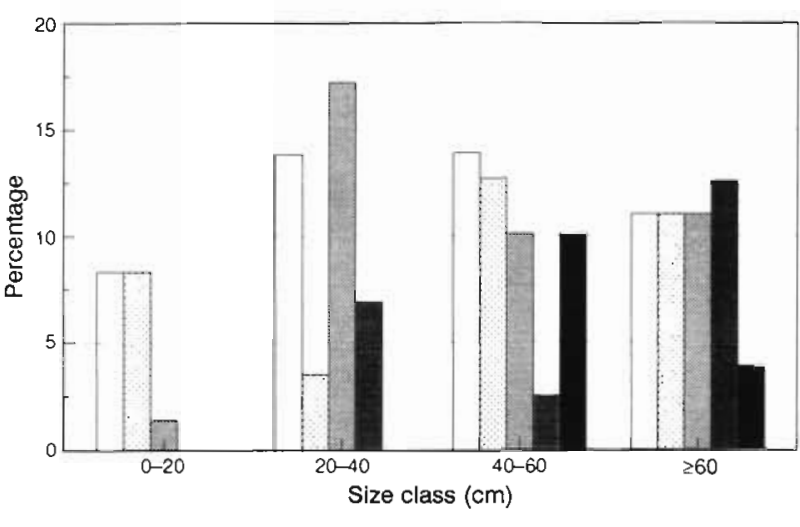

$\square$ very low level $\triangle$ low level

Fig. 4. Anguillicola crassus, Anguilla anguilla. Percentage of eels in different size classes with low, medium or high concentrations of eggs or $\mathrm{L}_{2}$-larvae in the swimbladder lumen

period $(85.2$ to $100 \%)$ and no seasonal pattern was observed. Mean abundance fluctuated between 8.3 (October) and 34.5 (February), but was generally higher from November until March 1991, as were also mean abundance of the small $\mathrm{L}_{3}$-larvae and variance to mean ratio. These changes however could be related to changes in size composition of the eel samples: mean length of eels caught was lowest from May until October and not one eel smaller than $30 \mathrm{~cm}$ was examined in winter. Also the large difference between March 1990 and March 1991 in mean abundance of the various stages makes it less plausible that any of those differences are significant trends.

The lack of a marked seasonal variation in prevalence is reflected in the population structure of the parasite (Fig. 5). The percentage of the various stages showed a pattern of irregular monthly fluctuations. Recruitment may take place in all months as $L_{3}$-larvae were present during the whole year. These larvae (small and grown) make up the largest part of the population during most of the year, which is possibly an indication of the relatively longer duration of this stage. The percentage of eels carrying small $L_{3}$-larvae fluctuated erratically, the percentage of eels with grown $\mathrm{L}_{3}$-larvae or $\mathrm{L}_{4}$-larvae remained more or less the same (Fig. 6). Juveniles of the new generation $\left(\mathrm{L}_{2}{ }^{-}\right.$ larvae) and mature females were found every month. The percentage of eels carrying $\mathrm{L}_{2}$-larvae varied between 20 and $62.5 \%$, this percentage being higher in autumn-winter than in spring-summer. Mean abundance of the adult stage was also higher in autumnwinter, which can be related to the fact that no eels smaller than $30 \mathrm{~cm}$ were sampled in that period. Adult remnants in the swimbladder lumen were found every month in various stages of decomposition.

\section{DISCUSSION}

Prevalence of infection of Anguillicola crassus in eels of the Albertcanal near Genk rose from $3.8 \%$ in 1986 (authors' unpubl. data) to $90.2 \%$ in 1990-1991, an explosive rise in infection prevalence in 4 years. This increase in infection prevalence with $A$. crassus has been observed in many European countries (e.g. Koops \& Hartmann 1989, Höglund et al. 1991, Möller et al. 1991). In most studies of $A$. crassus only the lumen of the swimbladder was investigated for the presence of adult worms (Koops \& Hartmann 1989, Höglund et al. 1991, Möller et al. 1991). However, the present study made it clear that most parasites are found in the swimbladder wall as $\mathrm{L}_{3}$-larvae. The Asian literature on the population biology of $A$. crassus never mentioned the occurrence of high levels of $\mathrm{L}_{3}$-larvae in the swimbladder wall (Kim et al. 1989), which might be due to a failure to look for them or the absence of $L_{3}$-larvae in Japanese eels may be genuine.

The assumption exists that fish in poor condition are mainly sucked into the filters of a power plant. Sprengel \& Lüchtenberg (1991) proved that the swimming speed of eels infected with Anguillicola crassus decreased and that this reduction increased with the number of (adult) parasites present. As parasitized fish swim more slowly, it is likely that they have less chance of escape and therefore occur at higher prevalences at the intake screens of a powerplant. Differences in $A$. crassus prevalence and abundance between eels from fykes and screens were not significant. The higher

Table 3. Anguillicola crassus, Anguilla anguilla. Spearman's rank correlation analyses between length, weight and abundance of nematodes in eels

\begin{tabular}{|ccc|}
\hline & Length & Weight \\
\hline Abundance of: & & $-0.20(\mathrm{p}=0.0002)$ \\
Wall worms & $-0.21 \quad(\mathrm{p}=0.0001)$ & $-0.13(\mathrm{p}=0.02)$ \\
Small $\mathrm{L}_{3}$-larvae & $-0.13 \quad(\mathrm{p}=0.01)$ & $-0.15(\mathrm{p}=0.007)$ \\
Grown $\mathrm{L}_{3}$-larvae & $-0.17 \quad(\mathrm{p}=0.002)$ & $0.33(\mathrm{p}=0.0001)$ \\
Lumen worms & $0.32(\mathrm{p}=0.0001)$ & $0.02(\mathrm{p}=0.67)$ \\
Total worms & $0.006(\mathrm{p}=0.92)$ & \\
\hline
\end{tabular}




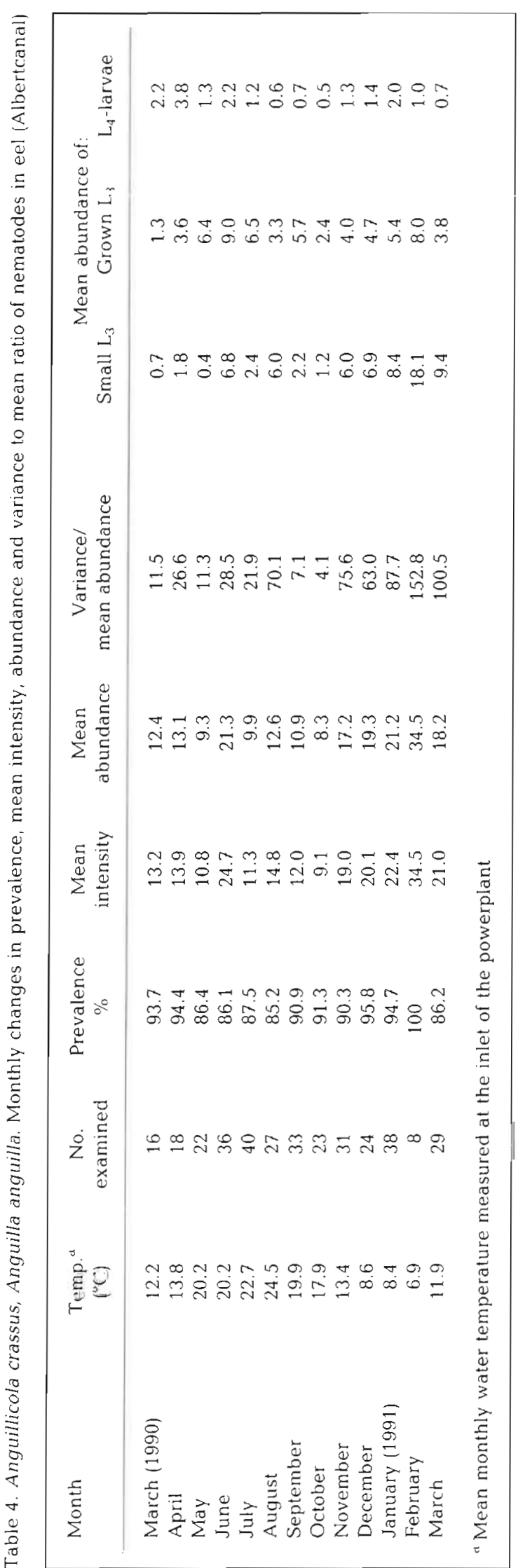

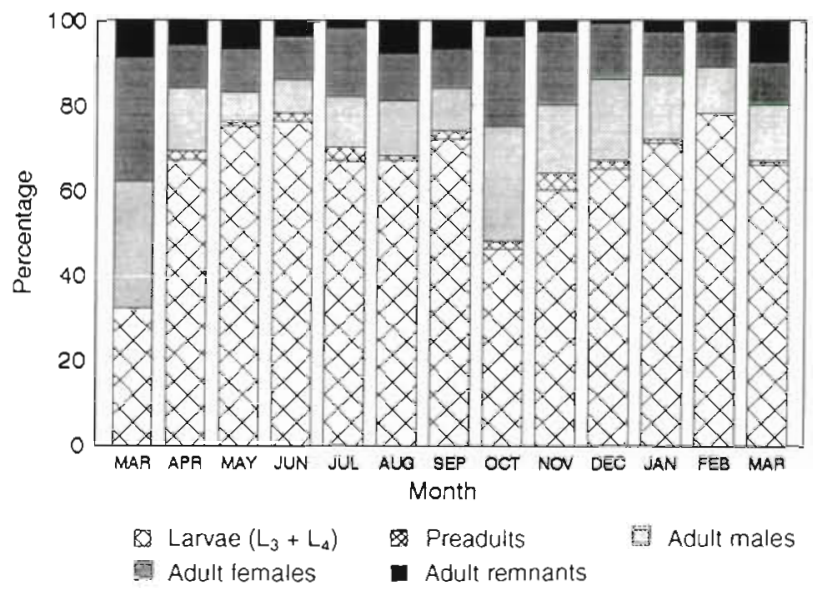

Fig. 5. Anguillicola crassus, Anguilla anguilla. Monthly changes in the relative percentage of the various nematode stages in eels

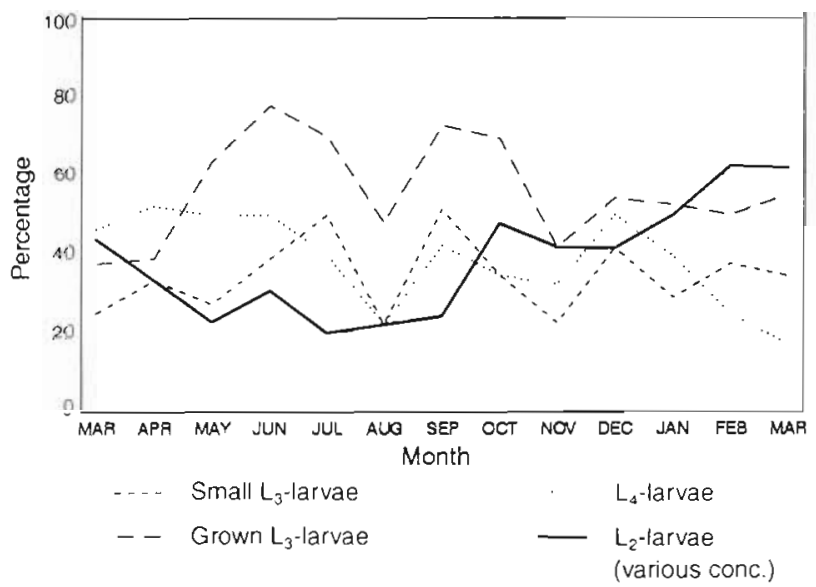

Fig. 6. Anguillicola crassus, Anguilla anguilla. Monthly changes in the percentage of eels carrying small $\mathrm{L}_{3}$-larvae, grown $\mathrm{L}_{3}$-larvae and $\mathrm{L}_{4}$-larvae in the swimbladder wall and $\mathrm{L}_{2}$-larvae in the lumen

mean number in the screens was caused by a few eels containing more than 100 wall worms. This might confirm the idea of Stemmer (1988) that eel health can be impaired by large numbers of $\mathrm{L}_{3}$-larvae, but as we cannot exclude the possibility of transmission on the screens, this may also have no biological meaning. The small difference in infection degree between eels from screens and fykes perhaps suggests an impact of remnants and decaying worms on the health of the eel.

It appears that there is no seasonal cycle in prevalence or abundance of Anguillicola crassus in its final host Anguilla anguilla. All stages are present throughout the year, indicating that reproduction takes place continuously. The observed differences in abundance are related to differences in size composition of the eel samples. No difference in prevalence between various 
size classes was observed, but in larger eels more adults and higher levels of $\mathrm{L}_{2}$-larvae were found, indicating that within small size classes the smaller swimbladder lumen impedes the normal development to a fully grown adult female: female worms of $A$. crassus easily reach $3 \mathrm{~cm}$ length, but not in swimbladders of ca $1 \mathrm{~cm}$ long. The negative correlation between eel length and total number of wall worms could also be explained by this. As development is impeded, relatively more grown $\mathrm{L}_{3}$ - and $\mathrm{L}_{4}$-larvae (with an abnormal appearance) are found dead in very small eels.

Eels exhibit marked seasonality in their activity patterns and feeding intensity: from November to March very low feeding levels were noted in various studies (Sinha \& Jones 1967, Conneely \& McCarthy 1986, de Nie 1988). This seasonality is not, however, expressed in the prevalence or abundance of Anguillicola crassus in the eel population. But, if the rate of development of the nematode is influenced by water temperature, being faster in summer, then levels of $\mathrm{L}_{3}$-larvae found in winter can overestimate the recruitment rate in winter and vice versa in summer.

Eels are known to become more piscivorous with increasing size (Tesch 1977). De Nie (1988) confirmed this observation and stated that the minimum length of piscivorous eel was ca $20 \mathrm{~cm}$. No difference in prevalence of Anguillicola crassus infection in various size classes might indicate the importance of a paratenic host for transmission. Although copepods - the obligatory intermediate hosts for $A$. crassus - may be inhaled accidentally, it is difficult to accept that they are responsible for the high numbers of $L_{3}$-larvae found in large eels. Studies on stomach contents of 622 eels in Lake Corrib, Ireland, did not reveal any evidence of feeding on copepods (Moriarty 1972). Non-piscivorous eels smaller than $20 \mathrm{~cm}$ never contained more than 14 small $\mathrm{L}_{3}$-larvae in this study, while larger eels carried up to 146 small $\mathrm{L}_{3}$-larvae. These small eels had relatively less adult worms, low concentrations of eggs and more remnants in the wall than larger eels. Overdispersion was lowest in the smallest size class $1<20 \mathrm{~cm}=$ non-piscivorous); as paratenic hosts concentrate infective stages, they cause greater overdispersion in the final host, which in turn enhances probability of reproductive success. From the point of view of $A$. crassus, which need large swimbladder lumens, i.e. large eels, to develop fully into mature adults and have a high reproductive capacity, paratenic hosts might be helpful for their long-term survival. Small eels feed on copepods but their swimbladder is too small, large eels are suitable for successful establishment but become more piscivorous. Study of A. crassus infection in other fish species at the Kolenhaven (Thomas \& Ollevier 1992) revealed that many teleost species carried $\mathrm{L}_{3}$ larvae. The most heavily infected species were benthic fishes such as ruffe Gymnocephalus cernua which had an infection prevalence of $95.7 \%$. Due to their bottomdwelling mode of life and restricting effect of the size of the mouth, eels prefer rather small fish (such as ruffe) inhabiting the lake bottom surface (Sinha 1969, de Nie 1988). Prevalence and abundance of $A$. crassus in eels longer than $50 \mathrm{~cm}$ were as high as in smaller eels indicating that at least in the Kolenhaven, paratenic hosts may play an important role in transmission. From this point of view it might be interesting to examine an eel population through time for $A$. crassus infection where no paratenic hosts occur.

Acknowledgements. The authors are most grateful to P. Van Damme and C. Kennedy for comments on the manuscript. The first author was supported by the National Science Foundation of Belgium.

\section{LITERATURE CITED}

Belpaire, C., De Charleroy, D., Grisez, L., Ollevier, F. (1989a). Spreading mechanisms of the swimbladder parasite Anguillicola crassus in the European eel Anguilla anguilla and its distribution in Belgium and Europe. European Inland Fishery Advisory Commission (EIFAC), Working Party on Eel, Porto, Portugal, May 29-June 3

Belpaire, C., De Charleroy, D., Thomas, K., Van Damme, P. Ollevier, F. (1989b). Effects of eel restocking on the distribution of the swimbladder nematode Anguillicola crassus in Flanders, Belgium. J. appl. Ichthyol. 5: 151-153

Chitwood, B., Chitwood, M. (1950) An introduction to nematology (Section 1: Anatomy). Monumental Printing, Baltimore

Conneely, J., McCarthy, T. (1986). Ecological factors influencing the composition of the parasite fauna of the European eel, Anguilla anguila (L.), in Ireland. J. Fish Biol. 28: 207-232

De Charleroy, D., Grisez, L., Thomas, K., Belpaire, C., Ollevier, F. (1990). The life cycle of Anguillicola crassus. Dis. aquat. Org. 8: 77-84

de Nie, H. W. (1988). Food, feeding and growth of the eel (Anguilla anguilla L.) in a Dutch eutrophic lake. Ph.D. dissertation, Agricultural University Wageningen, The Netherlands

Haenen, O. L. M., van Banning, P. (1990). Detection of larvae of Anguillicola crassus (an eel swimbladder nematode) in freshwater fish species. Aquaculture 87: 103-109

Höglund, J., Thomas, K. (1992). The black goby Gobius niger as a potential paratenic host for the parasitic nematode Anguillicola crassus in a thermal effluent of the Baltic. Dis. aquat. Org. 13: 175-180

Höglund, J., Andersson, J., Wickström, H., Reizenstein, M. (1991). The distribution of Anguillicola in Sweden - do thermal discharge areas serve as transmission foci? European Inland Fishery Advisory Commission (EIFAC), Working Party on Eel, Dublin, Ireland, 20-25 May

Kim, Y.-G., Kim, E.-B., Kim, J.-Y., Chun, S.-K. (1989). Studies on a nematode, Anguillicola crassa parasitic in the air bladder of the eel. J. Fish Pathol. 2: 1-18 (in Korean with English abstract)

Koops, H., Hartmann, F. (1989). Anguillicola-infestations in Germany and in German eel imports. J. appl. Ichthyol. 1: $41-45$ 
Kuwahara, A., Nimi, A., Itagaki, H. (1974). Studies on a nematode parasitic in the air bladder of the eel. I. Description of Anguillicola crassa n.sp. (Philometridae, Anguillicolidae). Jap. J. Parasitol. 23: 275-279

Margolis, L., Esch, G. W., Holmes, J. C., Kuris, A. M., Schad, G. A. (1982). The use of ecological terms in parasitology (report of an ad hoc committee of the American Society of Parasitologists) J. Parasitol. 68: 131-133

Moriarty, C. (1972). Studies of the eel A. anguilla in Ireland I. Ir. Fish. Invest. Ser. A. 10: 1-39

Möller, H., Holst, S., Lüchtenberg, H., Petersen, F. (1991) Infection of eel Anguilla anguilla from the River Elbe estuary with two nematodes, Anguillicola crassus and Pseudoterranova decipiens. Dis. aquat. Org. 11: 193-199

Petter, A. J., Cassone, J., Le Belle, N. (1990). Observations sur la biologie des premiers stades larvaires d'Anguillicola crassus, nématode parasite d'anguille. Ann. Parasitol. Hum. Comp. 65: 28-31

Sinha, V. R. P. (1969). A note on the feeding of larger eels Anguilla anguilla (L.). J. Fish. Biol. 1: 279-283

Sinha, V. R. P., Jones, J. W. (1967). On the food of the

Responsible Subject Editor: W. Körting, Hannover, Germany freshwater eels and their feeding relationship with the salmonids. J. Zool. 153: 119-137

Sprengel, G. Lüchtenberg, H. (1991). Infection by endoparasites reduces maximum swimming speed of European smelt Osmerus eperlanus and European eel Anguilla anguilla. Dis. aquat. Org. 11: 31-35

Stemmer, B. (1988). Untersuchungen der Larvalentwicklung von Anguillicola crassus (Nematoda: Dracunculoidea) in verschiedenen $Z$ wischenwirten. M.Sc. thesis, Ruhr University, Bochum

Tesch, F.-W. (1977). The eel: biology and management of anguillid eels. Chapman \& Hall, London (Translation: [1973]. Der Aal, Verlag Paul Parey, Hamburg)

Thomas, K., Ollevier, F. (1992). Paratenic hosts of the swimbladder nematode Anguillicola crassus. Dis. aquat. Org. 13: 165-174

van Banning, P., Haenen, O. L. M. (1990). Effects of the swimbladder nematode Anguillicola crassus in wild and farmed eel, Anguilla anguilla. In: Perkins, F. O., Cheng, T. C. (eds.) Pathology in marine science. Academic Press, New York, p. 317-330

Manuscript first received: July 8, 1992

Revised version accepted: August 25, 1992 